\title{
QUALIDADE E POTENCIAL DE CONSERVAÇÃO PÓS-COLHEITA DOS FRUTOS EM CULTIVARES BRASILEIRAS DE GOIABEIRA-SERRANA ${ }^{1}$
}

\author{
CASSANDRO VIDAL TALAMINI DO AMARANTE², CRISTIANO ANDRÉ STEFFENS², \\ THALITA DAL TOÉ BENINCÁ ${ }^{3}$, CRIZANE HACKBARTH ${ }^{3}, \mathrm{KARINE} \mathrm{LOUISE} \mathrm{DOS} \mathrm{SANTOS}^{4}$
}

RESUMO - Foi avaliada a manutenção da qualidade pós-colheita dos frutos em cultivares brasileiras de goiabeira-serrana. Frutos das cultivares Alcântara, Helena, Mattos e Nonante foram colhidos na maturação comercial, no município de São Joaquim-SC, e armazenados a $4 \pm 1{ }^{\circ} \mathrm{C}(90 \pm 5 \%$ UR), durante 21 dias, seguido de 8 e 48 h a $23 \pm 1{ }^{\circ} \mathrm{C}(75 \pm 5 \%$ UR). Foram avaliadas a composição mineral (N, K, Mg e Ca) na colheita e a qualidade dos frutos na colheita e após o armazenamento. Frutos da cultivar Nonante apresentaram na colheita maiores valores de acidez titulável (AT) $\mathrm{pH}$ e de atributos de textura, e menores valores de $\mathrm{pH}$ e da relação sólidos solúveis/acidez titulável (SS/AT), sendo que, após o armazenamento refrigerado, este comportamento foi reduzido, com menores diferenças em relação às demais cultivares. Frutos de 'Nonante' apresentaram também maiores teores de $\mathrm{K}$ na casca e polpa, e menores teores de $\mathrm{N}$ na polpa e, após o armazenamento refrigerado, cor verde menos intensa na casca e menor escurecimento de polpa. Em relação aos dados de colheita, após o armazenamento refrigerado, houve maior redução na AT (41\%) do que no teor de SS (8,6\%), o que ocasionou acentuado aumento na relação SS/AT (52,5\%), considerando valores médios das quatro cultivares. Isto evidencia que, em goiaba-serrana, os ácidos orgânicos representam o principal substrato respiratório durante o armazenamento, o que compromete a qualidade sensorial pelo aumento na relação SS/AT. Frutos de 'Alcântara' foram também avaliados quanto aos efeitos do dano mecânico na colheita e do retardo no armazenamento refrigerado, na qualidade após o armazenamento. $\mathrm{O}$ dano mecânico na colheita (dano por queda, a uma altura de $50 \mathrm{~cm}$, sobre uma superfície rígida) ocasionou mínimo comprometimento da qualidade após o armazenamento refrigerado. Frutos desta cultivar apresentaram redução na AT (31\%), textura da periderme (33\%) e força para a compressão (13\%), e aumento no pH (20\%) e na relação SS/AT (48\%), com o retardo no armazenamento refrigerado (de $0 \mathrm{~h}$ para $48 \mathrm{~h}$ a $18 \pm 2{ }^{\circ} \mathrm{C} / 70 \pm 5 \% \mathrm{UR}$ ).

Termos para indexação: Acca sellowiana Berg., dano mecânico, retardo no resfriamento, composição mineral, acidez, textura.

\section{QUALITY AND POSTHARVEST CONSERVATION POTENTIAL OF THE FRUIT IN BRAZILIAN CULTIVARS OF FEIJOA}

\begin{abstract}
This study was carried out to assess the postharvest quality preservation of the fruit in Brazilian cultivars of feijoa. Fruit of cultivars Alcântara, Helena, Mattos and Nonante were harvest at commercial maturity, in São Joaquim, southern Brazil, and cold stored at $4 \pm 1{ }^{\circ} \mathrm{C}(90 \pm 5 \% \mathrm{RH})$, during 21 days, followed by 8 and $48 \mathrm{~h}$ at $23 \pm 1{ }^{\circ} \mathrm{C}(75 \pm 5 \% \mathrm{RH})$. Fruit mineral content (N, K, Mg and Ca) was assessed at harvest, and fruit quality was assessed at harvest and after cold storage. At harvest, fruit of 'Nonante' had higher values of titratable acidity (TA), and texture attributes, and lower values of $\mathrm{pH}$ and soluble solids content/titratable acidity ratio (SSC/TA) than fruit of the other three cultivars. However, after cold storage, these differences were less expressive. Fruits of 'Nonante' had higher contents of K in the peel and flesh tissues, lower content of $\mathrm{N}$ in the flesh, and less intense green color of the peel and internal browning after cold storage, than fruit of the other three cultivars. In comparison to fruit quality assessed at harvest, following cold storage, there was a higher reduction of TA $(41 \%)$ than of SSC $(8.6 \%)$, with a resulting increase of the SSC/TA ratio $(52.5 \%)$, in an average for all cultivars. Therefore, organic acids are the main substrates used by respiration during storage in feijoa, and this might impair fruit sensory quality by increasing the SSC/TA ratio. Fruit of 'Alcântara' were also assessed for the effects of mechanical damage at harvest and cold storage delay on postharvest quality. The mechanical damage at harvest (by impact, with a $50 \mathrm{~cm}$ height drop of the fruit on a rigid surface) had minimal impairment of fruit quality after cold storage. Delaying the cold storage (from 0 h to $48 \mathrm{~h}$, at $\left.18 \pm 2{ }^{\circ} \mathrm{C} / 70 \pm 5 \% \mathrm{RH}\right)$ after harvest of 'Alcântara' reduced TA (31\%), periderm texture (33\%) and fruit compression force (13\%), and increased $\mathrm{pH}(20 \%)$ and SSC/TA ratio (48\%) during cold storage. Index terms: Acca sellowiana Berg., mechanical damage, cold storage delay, mineral composition, acidity, texture.
\end{abstract}

\footnotetext{
${ }^{1}$ (Trabalho 099-13). Recebido para publicação em: 01-03-2013. Aceito para publicação em: 20-11-2013.

${ }^{2}$ Dr., Prof. do Dept ${ }^{\circ}$ de Agronomia, CAV/UDESC, Lages-SC. Bolsista de Produtividade em Pesquisa do CNPq. E-mails: amarante@ cav.udesc.br; steffens@cav.udesc.br

${ }^{3}$ Eng. Agr., Mestrandos em Prod. Vegetal, CAV/UDESC, Lages-SC. E-mail: thalitabeninca@hotmail.com; crizanehackbarth@hotmail.com ${ }^{4}$ Dra., Prof., UFSC, Campus Universitário de Curitibanos. Curitibanos-SC. E-mail: karine.santos@ufsc.br
} 


\section{INTRODUÇÃO}

Dentre as fruteiras nativas com aptidão para a exploração comercial no Sul do Brasil, destacase a goiabeira-serrana [Acca sellowiana (Berg.) Burret, sinônimo Feijoa sellowiana Berg], também conhecida como guayabo verde ou guayabo del país no Uruguai e, na língua inglesa, como feijoa ou pineapple-guava (SANTOS et al., 2011).

A goiabeira-serrana é nativa do planalto meridional brasileiro e nordeste do Uruguai (THORP, 2006). Os frutos mostram grande potencial econômico, devido as suas qualidades organolépticas (sabor e aroma doce-acidulados e aroma penetrante), sendo consumidos in natura e empregados na fabricação de sucos, geleias, sorvetes e licores (SCHOTSMANS et al., 2011). A goiaba-serrana é fonte de vitaminas e minerais, apresenta atividade antibactericida, antioxidante e antialérgica, sendo que a presença de flavonoides auxilia na atividade imunológica, determinando respostas crônicas em processos inflamatórios (WESTON, 2010). Em estudos farmacológicos, foi demonstrado que os flavonoides presentes no fruto atuam seletivamente, causando apoptose em células tumorais mieloides, em casos de leucemia (BONTEMPO et al., 2007).

Em Santa Catarina, esta espécie vem sendo pesquisada desde 1986, pela Empresa de Pesquisa Agropecuária e Extensão Rural de Santa Catarina S.A. (EPAGRI), com o objetivo de selecionar genótipos superiores e desenvolver um sistema de produção que permita seu cultivo em escala comercial. Como resultado do trabalho da EPAGRI, foram lançadas, nos anos de 2007 e 2008, as quatro primeiras cultivares comerciais brasileiras de goiabaserrana: Alcântara (frutos colhidos em março), Mattos (frutos colhidos de meados de março até início de abril), Helena (frutos colhidos do segundo decêndio de abril até início de maio) e Nonante (frutos colhidos da segunda quinzena de abril até a primeira semana de maio) (SANTOS et al., 2011).

A goiaba serrana apresenta comportamento climatérico, sendo que a inibição da ação do etileno através do tratamento pós-colheita com 1-metilciclopropeno (1-MCP), a imediata refrigeração e o armazenamento em atmosfera controlada retardam o amadurecimento e aumentam o potencial de armazenamento dos frutos (AMARANTE et al., 2008; EAST et al., 2009). O fruto pode manifestar dano por frio quando mantido em temperaturas próximas a $0{ }^{\circ} \mathrm{C}$, sendo recomendado seu armazenamento a $4-5{ }^{\circ} \mathrm{C}$ (THORP, 2006; SCHOTSMANS et al., 2011). Estudos feitos com material genético cultivado no Brasil indicam que, mesmo sob refrigeração, o tempo de conservação é limitado, correspondendo acerca de 21 dias a $4^{\circ} \mathrm{C}$, seguido de dois dias de vida de prateleira a $20^{\circ} \mathrm{C}$ (AMARANTE et al., 2008; VELHO et al., 2011). A armazenagem por longos períodos, mesmo a 4-5 ${ }^{\circ} \mathrm{C}$, compromete a qualidade dos frutos, que apresentam redução no sabor, cujo declínio está associado a uma redução da acidez e da concentração de sólidos solúveis, bem como nos teores de vitamina C (HOFFMANN et al., 1994), e elevada incidência de escurecimento da polpa (THORP, 2006; SCHOTSMANS et al., 2011; VELHO et al., 2011).

O objetivo deste trabalho foi estudar a qualidade e o potencial de conservação póscolheita dos frutos, em quatro cultivares brasileiras de goiabeira-serrana (Alcântara, Helena, Mattos e Nonante), bem como avaliar os efeitos do dano mecânico e do retardo no resfriamento, na preservação da qualidade dos frutos durante o armazenamento refrigerado.

\section{MATERIAL E MÉTODOS}

Os frutos de goiabeira-serrana foram colhidos em pomar do Banco Ativo de Germoplasma (BAG), da estação experimental da EPAGRI, em São Joaquim-SC (latitude $28^{\circ} 16^{\prime} 40,02^{\prime}$ ' S, longitude $49^{\circ} 56^{\prime} 09,10^{\prime \prime}$ W e altitude de $1.400 \mathrm{~m}$ ), no ano de 2010, no ponto de colheita comercial, identificado pela sua facilidade do desprendimento da planta. No laboratório, os frutos foram selecionados pela uniformidade de tamanho, cor e ausência de defeitos, como má-formação e danos mecânicos. Com estes frutos, foram realizados e conduzidos três experimentos.

Avaliação da qualidade e do potencial de conservação pós-colheita em cultivares de goiabeira-serrana

Frutos das cultivares Alcântara, Helena, Mattos e Nonante foram avaliados quanto à composição mineral no momento da colheita, bem como na qualidade físico-química na colheita e após o armazenamento refrigerado.

$\mathrm{Na}$ colheita, foram realizadas análises dos teores de $\mathrm{N}, \mathrm{K}, \mathrm{Mg}$ e $\mathrm{Ca}\left(\mathrm{mg} \mathrm{kg}^{-1}\right.$ massa fresca), nos tecidos da casca (hipanto: epiderme externa + camadas hipodérmicas + parênquima externo) e polpa [ovário (epiderme interna + parênquima interno) + lóculo ovariano + tegumento carnoso + feixe placentário + sementes] dos frutos das quatro cultivares. Os teores de $\mathrm{N}$ foram determinados por semimicro-Kjeldahl, os de K por fotometria de chama e os de $\mathrm{Mg}$ e Ca por espectrofotometria de absorção 
atômica, segundo metodologia descrita por Amarante et al. (2012).

Os frutos das quatro cultivares foram avaliados quanto à qualidade na colheita, e após 21 dias de armazenamento a $4 \pm 1{ }^{\circ} \mathrm{C}(90 \pm 5 \%$ UR), seguido de 8 e 48 h a $23 \pm 1{ }^{\circ} \mathrm{C}(75 \pm 5 \%$ UR). Foram avaliados os atributos de textura da casca (epiderme externa e parênquima externo), força para a compressão do fruto, acidez titulável (AT), pH, teor de sólidos solúveis (SS), relação $\mathrm{SS} / \mathrm{AT}$, coloração da casca e da polpa, e incidência e severidade de escurecimento da polpa.

Os atributos de textura foram analisados com um texturômetro eletrônico TAXT-plus (Stable Micro Systems Ltda.), na região equatorial dos frutos (uma medição por fruto). Para a quantificação da textura da casca (força necessária para o rompimento da epiderme externa e penetração no parênquima externo), foi utilizada ponteira modelo PS2, com $2 \mathrm{~mm}$ de diâmetro, a qual foi introduzida a uma profundidade de $8 \mathrm{~mm}$, com velocidades pré-teste, teste e pós-teste de $10 ; 1$ e $10 \mathrm{~mm} \mathrm{~s}^{-1}$, respectivamente. A força para a compressão do fruto foi determinada usando-se uma plataforma, modelo $\mathrm{P} / 75$, com 75 $\mathrm{mm}$ de diâmetro, com velocidades de pré-teste, teste e pós-teste iguais a 10; 0,5 e $30 \mathrm{~mm} \mathrm{~s}^{-1}$, que exerceu uma força de compressão até uma deformação de 3 $\mathrm{mm}$ na superfície do fruto.

Os valores de AT (\% de ácido málico) foram obtidos por titulometria de amostra de suco extraída dos frutos $(10 \mathrm{~mL}$ de amostra diluída com $90 \mathrm{~mL}$ de água destilada), com solução de hidróxido de sódio $0,1 \mathrm{~N}$ até $\mathrm{pH} 8,1$. O pH do suco foi quantificado com um pHmetro de bancada.

Os teores de SS (\%) foram determinados com um refratômetro manual (Abbe Atago), utilizando-se do suco extraído conforme descrito para a AT, com correção da leitura para a temperatura de $20^{\circ} \mathrm{C}$.

A determinação da cor da casca (na região equatorial, duas leituras por fruto, em lados opostos do mesmo) e da polpa foi efetuada com o auxílio de um colorímetro Minolta CR 400, através da quantificação da luminosidade ('lightness'; $L$ ) e do ângulo 'hue' $\left(h^{\circ}\right)$. Para a medição da cor da polpa, os frutos foram cortados na região equatorial, com imediata leitura na região central da polpa, para evitar interferência do escurecimento após o corte, decorrente do processo de oxidação.

As análises de incidência (\%) e severidade de escurecimento da polpa foram feitas na avaliação realizada $48 \mathrm{~h}$ após o armazenamento refrigerado, imediatamente após a avaliação de cor da polpa com o colorímetro. A severidade foi avaliada com uma escala de 1 a 4 (1-ausente; 2-inicial; 3-moderado, e 4-severo)

\section{Efeito do dano mecânico na qualidade pós-colheita do fruto}

Frutos da cultivar Alcântara foram submetidos aos tratamentos sem (controle) e com dano mecânico após a colheita. $\mathrm{O}$ dano mecânico foi aplicado na região equatorial dos frutos, através da queda livre, de uma altura de $50 \mathrm{~cm}$, sobre uma superfície plana e indeformável. Sobre essa superfície, foi colocado pó de giz, permitindo que, a cada queda, o fruto fosse marcado na região do impacto e, posteriormente, assinalado com caneta preta de ponta macia, para a identificação do local da lesão. Antes da aplicação do dano, os frutos foram pesados individualmente, sendo uniformizados para apresentarem massa fresca similar $(95 \pm 5 \mathrm{~g})$ em ambos os tratamentos.

Após a aplicação dos tratamentos, os frutos foram armazenados durante 21 dias a $4 \pm 1{ }^{\circ} \mathrm{C}(90 \pm 5 \%$ UR). Os frutos foram avaliados 8 e $48 \mathrm{~h}$ após a remoção do armazenamento refrigerado, mantidos a $23 \pm 1{ }^{\circ} \mathrm{C}(75 \pm 5 \%$ UR), quanto aos atributos de textura da casca, força para a compressão, AT, pH, $\mathrm{SS}$, relação SS/AT, coloração da casca e da polpa, e incidência e severidade de escurecimento da polpa, segundo metodologia descrita anteriormente.

\section{Efeito do retardo no armazenamento} refrigerado na qualidade pós-colheita do fruto

Frutos da cultivar Alcântara foram colhidos e deixados durante $0 ; 24$ e 48 h a $18 \pm 2{ }^{\circ} \mathrm{C} / 70 \pm 5 \%$ UR (simulando temperatura diária média na região de São Joaquim-SC, nos meses de março a maio, durante o perído de colheita do fruto), seguido do armazenamento durante 21 dias a $4 \pm 1{ }^{\circ} \mathrm{C}(90 \pm 5 \%$ UR). Os frutos foram avaliados 8 e $48 \mathrm{~h}$ após a remoção do armazenamento refrigerado, sendo mantidos a $23 \pm 1{ }^{\circ} \mathrm{C}(75 \pm 5 \%$ UR). Os atributos avaliados foram: textura da casca, força para a compressão do fruto, $\mathrm{AT}, \mathrm{pH}, \mathrm{SS}$, relação $\mathrm{SS} /$ AT, coloração da casca e da polpa, e incidência e severidade de escurecimento da polpa, segundo metodologia descrita anteriormente.

\section{Análise estatística dos dados}

Em todos os experimentos, foi utilizado o delineamento experimental inteiramente casualizado, com dez repetições, cada repetição com seis frutos.

Os dados foram submetidos à análise da variância (ANOVA), com o programa SAS (SAS Institute, 2002). Dados em valores percentuais foram transformados para arco-seno $[(\mathrm{x}+5) / 100]^{1 / 2}$, e de severidade (escala de 1 a 4) transformados para 
$\mathrm{x}^{1 / 2}$, antes de serem submetidos à ANOVA. Nos dois primeiros experimentos, as médias dos tratamentos foram comparadas pelo teste de Tukey $(\mathrm{p}<0,05)$. $\mathrm{O}$ efeito de tempo, no retardo no armazenamento refrigerado sobre os atributos de qualidade, foi analisado por meio de contrastes ortogonais polinomiais (linear e quadrático; $\mathrm{p}<0,05$ ).

\section{RESULTADOS E DISCUSSÃO}

No primeiro experimento, observa-se que os teores de $\mathrm{N}, \mathrm{K}$ e $\mathrm{Mg}$ foram similares entre os tecidos de casca e de polpa, independentemente da cultivar (Tabela 1). No entanto, os teores de Ca na casca ( $\sim 163 \mathrm{mg} \mathrm{kg}^{-1}$ de peso fresco) foram cerca de 2,4 vezes maiores do que na polpa ( $\sim 67 \mathrm{mg} \mathrm{kg}^{-1}$ de peso fresco), na média das quatro cultivares (Tabela 1). Em outras espécies cultivadas no Sul do Brasil, como é o caso de maçãs, os teores de $\mathrm{N}, \mathrm{K}, \mathrm{Mg}$ e Ca são muito maiores na casca do que na polpa (AMARANTE et al., 2006). Isto demostra que, em goiaba-serrana, este comportamento ocorre apenas para o $\mathrm{Ca}$.

Os teores de Ca na polpa das quatro cultivares de goiaba-serrana encontram-se na faixa reportada por outros autores, de 40 a $150 \mathrm{mg} \mathrm{kg}^{-1}$ de peso fresco, em cultivos na Nova Zelândia (THORP, 2006; SCHOTSMANS et al., 2011) e Colômbia (LETERME et al., 2006). Os teores de $\mathrm{N}$ e K na polpa (pouco superiores a $1.200 \mathrm{mg} \mathrm{kg}^{-1}$ de peso fresco, na média das quatro cultivares) são próximos do valor reportado na Nova Zelândia, que é de $\sim 1.300 \mathrm{mg} \mathrm{kg}^{-1}$ de peso fresco, para ambos os elementos minerais (THORP, 2006; SCHOTSMANS et al., 2011). No entanto, em frutos coletados na Colômbia, foram reportados menores teores de $\mathrm{K}$ na polpa, de 225,2 $\mathrm{mg} \mathrm{kg}^{-1}$ de peso fresco (LETERME et al., 2006). Os teores médios de $\mathrm{Mg}$ na polpa das quatro cultivares (9-15 $\mathrm{mg} \mathrm{kg}^{-1}$ de peso fresco) foram menores do que aqueles encontrados na Colômbia, de 27,5 mg kg-1 de peso fresco (LETERME et al., 2006), e muito inferiores aos valores reportados na Nova Zelândia, de 60-90 $\mathrm{mg} \mathrm{kg}^{-1}$ de peso fresco (THORP, 2006; SCHOTSMANS et al., 2011).

Apenas para o teor de $\mathrm{Mg}$ na casca não houve diferença significativa entre as cultivares (Tabela 1). A cultivar Mattos apresentou, na casca, os maiores teores de $\mathrm{N}$ e menores teores de $\mathrm{K} \mathrm{e} \mathrm{Ca}$. A cultivar Nonante apresentou, em relação às demais cultivares, maiores teores de $\mathrm{K}$ na casca e na polpa, e menores teores de $\mathrm{N}$ na polpa (Tabela 1).

É esperada diferença entre genótipos quanto à composição mineral nos frutos, como observado na Tabela 1. A variabilidade reportada para os teores de N, K, Mg e Ca na polpa, em trabalhos publicados por outros autores, e as diferenças em relação aos valores obtidos nas quatro cultivares brasileiras de goiaba-serrrana parecem refletir, além de diferenças genéticas, condições edafoclimáticas e sistemas de produção/manejo das plantas, que interferem na composição mineral dos frutos (AMARANTE et al., 2012).

Houve diferença significativa entre cultivares de goiaba-serrana na colheita, para a maioria dos atributos físico-químicos de qualidade avaliados, exceto para o teor de SS (Tabela 2).

Os valores de SS na colheita estão dentro da faixa reportada por outros autores (10-16\%) em goiaba-serrana (SCHOTSMANS et al., 2011), sendo variáveis em função da cultivar, estádio de maturação e local de produção (AL-HARTHY, 2010). O teor de SS foi diferente entre as cultivares apenas quando quantificado após $48 \mathrm{~h}$ da remoção do armazenamento refrigerado, com os maiores valores sendo observados na cultivar Mattos (Tabela 2). Houve redução no teor de SS, após armazenamento refrigerado, na média de todas as cultivares, de $5 \%$ e $12 \%$, após 8 h e $48 \mathrm{~h} \mathrm{a} 23^{\circ} \mathrm{C}$, respectivamente, em relação ao valor quantificado na colheita.

$\mathrm{Na}$ colheita, a AT foi maior e o $\mathrm{pH}$ menor na cultivar Nonante, não diferindo entre as demais cultivares (Tabela 2). Os valores de AT na colheita estão dentro da faixa reportada por Al-harthy (2010) em goiaba-serrana, entre 1,5-3,0 \% de ácido málico, mas maiores do que aqueles descritos por Schotsmans et al. (2011), entre 0,8 e 1,6\%. AAT quantificada após $48 \mathrm{~h}$ da remoção do armazenamento refrigerado foi superior nas cultivares Nonante e Mattos, comparativamente às cultivares Alcântara e Helena (Tabela 2). Houve expressiva redução na AT, após armazenamento refrigerado, sendo, na média de todas as cultivares, de $36 \%$ e $46 \%$, após 8 h e 48 h a $23{ }^{\circ} \mathrm{C}$, respectivamente, em relação ao valor quantificado na colheita. Já o pH apresentou pequena alteração após o armazenamento refrigerado, mostrando que o suco de frutos apresenta poder tamponante, devido aos sais minerais e à pectina presentes (GONÇALVES et al., 2006), fazendo com que as alterações na AT não afetem significativamente os valores de $\mathrm{pH}$.

A relação SS/AT na colheita também foi maior na cultivar Nonante, porém não diferiu das demais cultivares após o armazenamento refrigerado (Tabela 2). Devido à maior redução na AT do que no teor de SS, houve grande aumento na relação SS/AT após o armazenamento. Na média de todas as cultivares, a relação SS/AT aumentou em $42 \%$ e $63 \%$, após $8 \mathrm{~h}$ e $48 \mathrm{~h}$ a $23{ }^{\circ} \mathrm{C}$, respectivamente, em relação ao valor quantificado na colheita. Os resultados evidenciam que, em goiaba serrana, os 
ácidos orgânicos representam o principal substrato respiratório durante o armazenamento, o que compromete a qualidade sensorial pelo aumento na relação SS/AT.

A cultivar Nonante apresentou maiores valores de textura da casca (epiderme externa e parênquima externo), e de força para a compressão do fruto na colheita, e maiores valores de força para a compressão do fruto $8 \mathrm{~h}$ e $48 \mathrm{~h}$ após remoção do armazenamento refrigerado, em relação às demais cultivares (Tabela 2). No entanto, após o armazenamento refrigerado, frutos da cultivar Nonante apresentaram maiores valores de textura da casca apenas em relação a 'Helena', na avaliação feita após 8 h e 48 h, e em relação a 'Mattos', na avaliação feita após $48 \mathrm{~h}$. Considerando o comportamento médio das quatro cultivares, a redução da textura da epiderme externa, em relação ao valor quantificado na colheita, foi de $12 \%$ e $25 \%$, após 8 h e 48 h a 23 ${ }^{\circ} \mathrm{C}$, respectivamente; e para textura do parênquima externo, a redução foi de $25 \%$ e $49 \%$, após 8 h e 48 h a $23{ }^{\circ} \mathrm{C}$, respectivamente. Portanto, o parênquima externo, devido possivelmente a diferenças estruturais e maior atividade de enzimas de degradação de parede celular, em relação à epiderme externa, apresenta maior perda de textura durante o amadurecimento. Isto acarreta perda na resistência do fruto à deformação. Desta forma, a força para a compressão do fruto pode ser considerada como atributo adequado para avaliar o amadurecimento dos frutos, bem como para segregar genótipos de goiaba serrana quanto à qualidade pós-colheita.

A cultivar Nonante apresentou, em relação às demais cultivares, a cor da casca menos verde, após o armazenamento refrigerado, caracterizada pelos menores valores de $h^{\circ}$ e maiores valores de $L$ (Tabela 4). Esta cultivar apresentou também, tanto na colheita como após armazenamento refrigerado, maiores valores de $L$ da polpa (coloração mais clara), em relação às demais cultivares (Tabela 4).

Em relação às demais cultivares, frutos da cultivar Nonante apresentaram menor incidência e severidade de escurecimento da polpa, na avaliação feita $48 \mathrm{~h}$ após remoção do armazenamento refrigerado. $\mathrm{Na}$ 'Nonante', a incidência de escurecimento da polpa foi de $64,6 \%$, sendo de 84,5\% em 'Helena' e de 100\% em 'Alcântara' e 'Mattos'. A severidade de escurecimento foi de índice 2,0 em 'Nonante', 2,2 em 'Helena', 2,4 em 'Mattos' e 2,9 em 'Alcântara'. Isto indica que, em frutos de 'Nonante', além de uma polpa mais clara na colheita, ocorre menor escurecimento deste tecido durante o armazenamento, que é uma das características que mais limitam o armazenamento refrigerado de goiaba-serrana (THORP, 2006; SCHOTSMANS et al., 2011). No entanto, mesmo na cultivar Nonante, os níveis de comprometimento da qualidade, ocasionada pelo escurecimento, são muito altos, considerando que os frutos foram armazenados durante 21 dia a $4 \pm 1{ }^{\circ} \mathrm{C}$, seguido de $48 \mathrm{~h}$ a $23 \pm 1{ }^{\circ} \mathrm{C}$. Na Nova Zelândia, os frutos das cultivares comerciais de goiaba-serrana podem ser armazenados a $4-5{ }^{\circ} \mathrm{C}$ por até 30 dias, seguido de 5 dias à temperatura ambiente, com menores níveis de escurecimento de polpa (THORP, 2006; SCHOTSMANS et al., 2011). Existe uma relação positiva entre níveis de atividade da enzima polifenoloxidase (PPO) e o escurecimento de polpa do fruto em genótipos de goiaba-serrana (SCHOTSMANS et al., 2011). Portanto, em futuros trabalhos de melhoramento de goiaba-serrana do BAG da Epagri, justifica-se a avaliação de atividade de PPO e de escurecimento de polpa dos frutos durante o armazenamento refrigerado, visando à seleção de genótipos com potencial de exploração comercial menos suscetíveis ao distúrbio.

O menor escurecimento de polpa em Nonante, após o armazenamento refrigerado, pode ser resultado do menor teor de $\mathrm{N}$ na polpa. Frutos com elevados teores de $\mathrm{N}$ apresentam maiores taxas respiratórias e de produção de etileno em pós-colheita, resultando em antecipação do amadurecimento e senescência, e isto possivelmente acelera a ocorrência de escurecimento de polpa, especialmente em frutos com baixos teores de $\mathrm{Ca}$ (AMARANTE et al., 2012).

No segundo experimento, foi observado mínimo comprometimento da qualidade em resposta ao dano mecânico, avaliada após 21 dias de armazenamento refrigerado (dados não apresentados). Apenas a força para compressão, avaliada 8 h após a remoção do armazenamento refrigerado, foi significativamente menor em frutos com dano (20,1 N) do que em frutos sem dano (30,8 N). A AT, avaliada $48 \mathrm{~h}$ após a remoção dos frutos do armazenamento, foi maior em frutos com dano $(1,4 \%)$ do que em frutos sem dano $(1,0 \%)$. Os demais atributos de qualidade, avaliados $8 \mathrm{~h}$ e $48 \mathrm{~h}$ após remoção do armazenamento refrigerado, não diferiram entre os tratamentos. $\mathrm{O}$ dano por impacto não ocasionou alteração visível no aspecto visual externo dos frutos.

O dano, dependendo da espécie, cultivar, temperatura e estádio de maturação do fruto, e energia de impacto, pode ou não ocasionar perdas de textura, SS e AT (DURIGAN et al., 2005). Os resultados obtidos mostram que o fruto de 'Alcântara' apresenta pouco comprometimento na qualidade, ao nível de dano avaliado (queda de uma altura de $50 \mathrm{~cm}$ 
sobre superfície rígida indeformável). No entanto, é necessário avaliar se o mesmo tipo de resposta ocorre nos frutos das demais cultivares de goiaba-serrana, e a diferentes tipos e níveis de dano mecânico, aplicados em diferentes estádios de amadurecimento dos frutos após a colheita.

No terceiro experimento, foi observado maior comprometimento da qualidade com o atraso na refrigeração, quando os frutos foram avaliados $48 \mathrm{~h}$ após remoção do armazenamento refrigerado (Tabela 4). Nos frutos avaliados $8 \mathrm{~h}$ após a remoção do armazenamento refrigerado, apenas a força para a compressão do fruto reduziu-se significativamente com o retardo na refrigeração (com valores de 41,$8 ; 38,0$ e $31,8 \mathrm{~N}$, para frutos com atraso de 0; 24 e $48 \mathrm{~h}$ para o armazenamento refrigerado, respectivamente). Nos frutos avaliados $48 \mathrm{~h}$ após a remoção do armazenamento refrigerado, observouse, com o retardo do armazenamento refrigerado, redução significativa na $\mathrm{AT}$, aumento no $\mathrm{pH}$ e na relação SS/AT e redução na textura do parênquima externo e na força para compressão do fruto (Tabela 4). Convém salientar que, após a colheita, os frutos foram mantidos a $18 \pm 2{ }^{\circ} \mathrm{C}$, procurando simular a temperatura diária média na região de São Joaquim-SC, nos meses de março a maio (período de colheita de goiaba-serrana). A exposição dos frutos a temperaturas mais altas do que a utilizada neste trabalho, associada ao prolongamento no tempo para a refrigeração, certamente terá efeitos maiores na perda da qualidade dos frutos após o armazenamento refrigerado.

Os resultados obtidos demonstram que, de forma geral, a cultivar Nonante, cuja maturação dos frutos é a mais tardia (ocorrendo da segunda quinzena de abril até a primeira semana de maio) entre as cultivares já lançadas pela EPAGRI, apresenta melhor qualidade físico-química na colheita, a qual se mantém após o armazenamento refrigerado, além de apresentar menor escurecimento de polpa. Em todas as cultivares, o comprometimento na qualidade sensorial está associada à elevada queda na AT durante o armazenamento refrigerado. A alta atividade metabólica do fruto exige o imediato armazenamento refrigerado, visando a preservar sua qualidade pós-colheita.

TABELA 1 - Composição mineral na casca e polpa dos frutos na colheita, em diferentes cultivares de goiabeira-serrana (Acca sellowiana).

\begin{tabular}{ccccc}
\hline \multirow{2}{*}{ Cultivar } & \multicolumn{5}{c}{ Teores minerais $\left(\mathrm{mg} \mathrm{kg}^{-1}\right.$ de massa fresca) } \\
\cline { 2 - 5 } & $\mathrm{N}$ & $\mathrm{K}$ & $\mathrm{Mg}$ & $\mathrm{Ca}$ \\
\hline \multirow{4}{*}{ Alcântara } & $1265 \mathrm{~b}^{*}$ & $902 \mathrm{bc}$ & $12,3 \mathrm{~ns}$ & $170,2 \mathrm{a}$ \\
Mattos & $1440 \mathrm{a}$ & $786 \mathrm{c}$ & 13,2 & $140,2 \mathrm{~b}$ \\
Helena & $1268 \mathrm{~b}$ & $1014 \mathrm{~b}$ & 13,2 & $167,0 \mathrm{a}$ \\
Nonante & $1271 \mathrm{~b}$ & $1674 \mathrm{a}$ & 12,7 & $173,3 \mathrm{a}$ \\
Média & 1311 & 1094 & 12,9 & 162,7 \\
CV (\%) & 9,7 & 21,3 & 21,0 & 7,9 \\
\hline & \multicolumn{4}{c}{ POLPA } \\
Alcântara & $1349 \mathrm{a}$ & $1190 \mathrm{~b}$ & $15,3 \mathrm{a}$ & $74,3 \mathrm{a}$ \\
Mattos & $1310 \mathrm{ab}$ & $1074 \mathrm{~b}$ & $9,7 \mathrm{~b}$ & $63,5 \mathrm{~b}$ \\
Helena & $1259 \mathrm{~b}$ & $1246 \mathrm{~b}$ & $9,6 \mathrm{~b}$ & $67,3 \mathrm{ab}$ \\
Nonante & $1066 \mathrm{c}$ & $1626 \mathrm{a}$ & $9,7 \mathrm{~b}$ & $63,8 \mathrm{~b}$ \\
Média & 1246 & 1284 & 11,1 & 67,2 \\
CV (\%) & 6,5 & 14,8 & 8,0 & 12,1 \\
\hline
\end{tabular}

*Valores seguidos da mesma letra, nas colunas, não diferem entre si, pelo teste de Tukey $(\mathrm{p}<0,05)$. ns: não significativo $(\mathrm{p}>0,05)$. 
TABELA 2 - Atributos de qualidade dos frutos, em diferentes cultivares de goiabeira-serrana (Acca sellowiana), na colheita e após armazenamento refrigerado (21 dias a $\left.4 \pm 1{ }^{\circ} \mathrm{C} / 90 \pm 5 \% \mathrm{UR}\right)$, seguido de 8 h e $48 \mathrm{~h}$ a $23 \pm 1^{\circ} \mathrm{C}(75 \pm 5 \%$ UR $)$.

\begin{tabular}{|c|c|c|c|}
\hline \multirow{2}{*}{ Cultivar } & \multirow{2}{*}{ Colheita } & \multicolumn{2}{|c|}{ Após armazenamento } \\
\hline & & $8 \mathrm{~h}$ & $48 \mathrm{~h}$ \\
\hline & \multicolumn{3}{|c|}{ Sólidos solúveis (SS; \%) } \\
\hline Alcântara & $10,1^{\mathrm{ns}}$ & $8,9^{\mathrm{ns}}$ & $8,6 b^{*}$ \\
\hline Mattos & 12,1 & 11,0 & $12,3 \mathrm{a}$ \\
\hline Helena & 12,0 & 10,1 & $8,7 \mathrm{~b}$ \\
\hline Nonante & 10,4 & 11,9 & $9,6 \mathrm{~b}$ \\
\hline Média & 11,1 & 10,5 & 9,8 \\
\hline \multirow[t]{2}{*}{$C V(\%)$} & 23,7 & 25,8 & 13,7 \\
\hline & \multicolumn{3}{|c|}{ Acidez titulável (AT; \% de ácido málico) } \\
\hline Alcântara & $1,85 \mathrm{~b}$ & $1,13^{\text {ns }}$ & $0,84 \mathrm{~b}$ \\
\hline Mattos & $1,89 \mathrm{~b}$ & 1,20 & $1,45 \mathrm{a}$ \\
\hline Helena & $1,63 \mathrm{~b}$ & 1,56 & $0,81 \mathrm{~b}$ \\
\hline Nonante & $2,89 \mathrm{a}$ & 1,39 & $1,35 \mathrm{a}$ \\
\hline Média & 2,07 & 1,32 & 1,11 \\
\hline \multirow[t]{2}{*}{$C V(\%)$} & 25,4 & 32,4 & 28,5 \\
\hline & \multicolumn{3}{|c|}{ Relação SS/AT } \\
\hline Alcântara & $6,0 \mathrm{a}$ & $7,9^{\mathrm{ns}}$ & $11,5^{\mathrm{ns}}$ \\
\hline Mattos & $6,9 \mathrm{a}$ & 9,5 & 8,8 \\
\hline Helena & $7,7 \mathrm{a}$ & 8,1 & 11,8 \\
\hline Nonante & $3,6 \mathrm{~b}$ & 8,5 & 7,3 \\
\hline Média & 6,0 & 8,5 & 9,8 \\
\hline \multirow[t]{2}{*}{$C V(\%)$} & 41,5 & 37,9 & 37,4 \\
\hline & & $\mathrm{pH}$ & \\
\hline Alcântara & $3,5 \mathrm{a}$ & $3,1 \mathrm{~b}$ & $3,7^{\mathrm{ns}}$ \\
\hline Mattos & $3,1 \mathrm{a}$ & $2,9 \mathrm{~b}$ & 3,3 \\
\hline Helena & $3,2 \mathrm{a}$ & $3,7 \mathrm{a}$ & 3,7 \\
\hline Nonante & $2,0 \mathrm{~b}$ & $2,9 \mathrm{~b}$ & 3,1 \\
\hline Média & 3,0 & 3,2 & 3,5 \\
\hline \multirow[t]{2}{*}{$C V(\%)$} & 19,3 & 11,0 & 13,7 \\
\hline & \multicolumn{3}{|c|}{ Textura da epiderme externa $(\mathrm{N})$} \\
\hline Alcântara & $9,5 \mathrm{~b}$ & 9,6 a & $8,4 \mathrm{a}$ \\
\hline Mattos & $9,6 \mathrm{~b}$ & $8,4 \mathrm{a}$ & $5,9 \mathrm{~b}$ \\
\hline Helena & $6,0 \mathrm{c}$ & $5,3 \mathrm{~b}$ & $5,8 \mathrm{~b}$ \\
\hline Nonante & $11,7 \mathrm{a}$ & $9,0 \mathrm{a}$ & $7,4 \mathrm{a}$ \\
\hline Média & 9,2 & 8,1 & 6,9 \\
\hline \multirow[t]{2}{*}{$C V(\%)$} & 14,5 & 20,1 & 12,6 \\
\hline & \multicolumn{3}{|c|}{ Textura do parênquima externo $(\mathrm{N})$} \\
\hline Alcântara & $3,5 \mathrm{~b}$ & $3,6 \mathrm{a}$ & $2,5 \mathrm{a}$ \\
\hline Mattos & $4,0 \mathrm{~b}$ & $3,0 \mathrm{ab}$ & $1,9 \mathrm{~b}$ \\
\hline Helena & $1,9 \mathrm{c}$ & $1,8 \mathrm{~b}$ & $1,5 \mathrm{~b}$ \\
\hline Nonante & $7,7 \mathrm{a}$ & $4,3 \mathrm{a}$ & $2,9 \mathrm{a}$ \\
\hline Média & 4,3 & 3,2 & 2,2 \\
\hline \multirow[t]{2}{*}{$C V(\%)$} & 30,5 & 28,2 & 15,5 \\
\hline & \multicolumn{3}{|c|}{ Força para compressão do fruto $(\mathrm{N})$} \\
\hline Alcântara & $37,3 \mathrm{c}$ & $33,2 \mathrm{bc}$ & $26,7 \mathrm{bc}$ \\
\hline Mattos & $51,2 \mathrm{~b}$ & $42,0 \mathrm{~b}$ & $28,3 \mathrm{~b}$ \\
\hline Helena & $40,5 \mathrm{bc}$ & $25,2 \mathrm{c}$ & $20,7 \mathrm{c}$ \\
\hline Nonante & $105,5 \mathrm{a}$ & $55,2 \mathrm{a}$ & $54,4 \mathrm{a}$ \\
\hline Média & 58,6 & 38,9 & 32,5 \\
\hline$C V(\%)$ & 25,7 & 17,7 & 15,1 \\
\hline
\end{tabular}

*Valores seguidos da mesma letra, nas colunas, não diferem entre si, pelo teste de Tukey $(\mathrm{p}<0,05)$. ns: não significativo $(\mathrm{p}>0,05)$. 
TABELA 3 - Coloração (luminosidade $=L$; e ângulo 'hue' $=h^{\circ}$ ) da casca e polpa dos frutos, em diferentes cultivares de goiabeira-serrana (Acca sellowiana), na colheita e após armazenamento refrigerado (21 dias a $\left.4 \pm 1{ }^{\circ} \mathrm{C} / 90 \pm 5 \% \mathrm{UR}\right)$, seguido de $8 \mathrm{~h}$ e $48 \mathrm{~h}$ a $23 \pm 1^{\circ} \mathrm{C}(75 \pm 5 \% \mathrm{UR})$.

\begin{tabular}{|c|c|c|c|}
\hline \multirow{2}{*}{ Cultivar } & \multirow{2}{*}{ Colheita } & \multicolumn{2}{|c|}{ Após armazenamento } \\
\hline & & $8 \mathrm{~h}$ & $48 \mathrm{~h}$ \\
\hline & \multicolumn{3}{|c|}{ CASCA } \\
\hline & \multicolumn{3}{|c|}{$L$} \\
\hline Alcântara & $45,1 \mathrm{a}^{*}$ & $45,6 \mathrm{~b}$ & $46,3^{\text {ns }}$ \\
\hline Mattos & $43,2 \mathrm{~b}$ & $43,2 \mathrm{c}$ & 45,8 \\
\hline Helena & $42,8 \mathrm{~b}$ & $44,2 \mathrm{bc}$ & 45,8 \\
\hline Nonante & $43,1 \mathrm{~b}$ & $48,1 \mathrm{a}$ & 47,1 \\
\hline Média & 43,6 & 45,3 & 46,3 \\
\hline \multirow[t]{2}{*}{$C V(\%)$} & 3,7 & 3,0 & 3,1 \\
\hline & \multicolumn{3}{|c|}{$h^{o}$} \\
\hline Alcântara & $122,6 \mathrm{~b}$ & $122,7 \mathrm{a}$ & $122,3 \mathrm{a}$ \\
\hline Mattos & $124,5 \mathrm{a}$ & $122,1 \mathrm{a}$ & $123,9 \mathrm{a}$ \\
\hline Helena & $123,7 \mathrm{ab}$ & $122,6 \mathrm{a}$ & $122,6 \mathrm{a}$ \\
\hline Nonante & $122,8 \mathrm{~b}$ & $116,0 \mathrm{~b}$ & $119,8 \mathrm{~b}$ \\
\hline Média & 123,4 & 120,9 & 122,2 \\
\hline \multirow[t]{3}{*}{$\mathrm{CV}(\%)$} & 0,8 & 1,4 & 0,8 \\
\hline & \multicolumn{3}{|c|}{ POLPA } \\
\hline & \multicolumn{3}{|c|}{$L$} \\
\hline Alcântara & $56,7 \mathrm{~b}$ & $52,1 \mathrm{~b}$ & $47,3 \mathrm{~b}$ \\
\hline Mattos & $59,0 \mathrm{~b}$ & $52,4 \mathrm{~b}$ & $47,8 \mathrm{~b}$ \\
\hline Helena & $65,7 \mathrm{ab}$ & $45,4 \mathrm{c}$ & $44,8 \mathrm{~b}$ \\
\hline Nonante & $70,7 \mathrm{a}$ & $59,1 \mathrm{a}$ & $64,2 \mathrm{a}$ \\
\hline Média & 63,0 & 52,3 & 51,0 \\
\hline \multirow[t]{2}{*}{$C V(\%)$} & 13,6 & 8,9 & 15,3 \\
\hline & \multicolumn{3}{|c|}{$h^{o}$} \\
\hline Alcântara & $93,0 \mathrm{~b}$ & $93,4^{\mathrm{ns}}$ & $87,7 \mathrm{c}$ \\
\hline Mattos & $95,7 \mathrm{ab}$ & 95,4 & 89,6 bc \\
\hline Helena & $100,3 \mathrm{a}$ & 93,6 & $93,5 \mathrm{ab}$ \\
\hline Nonante & $99,2 \mathrm{a}$ & 92,8 & $97,6 \mathrm{a}$ \\
\hline Média & 97,1 & 93,8 & 92,1 \\
\hline$C V(\%)$ & 3,7 & 3,2 & 3,2 \\
\hline
\end{tabular}

*Valores seguidos da mesma letra, nas colunas, não diferem entre si, pelo teste de Tukey $(\mathrm{p}<0,05)$. ns: não significativo $(\mathrm{p}>0,05)$. 
TABELA 4 - Efeito do tempo de retardo no armazenamento, na qualidade pós-colheita de frutos de goiabaserrana (Acca sellowiana), armazenados sob refrigeração $\left(4 \pm 1{ }^{\circ} \mathrm{C} / 90 \pm 5 \% \mathrm{UR}\right)$ durante 21 dias, seguido de $48 \mathrm{~h}$ a $23 \pm 1{ }^{\circ} \mathrm{C}(75 \pm 5 \% \mathrm{UR})$.

\begin{tabular}{ccccccc}
\hline $\begin{array}{c}\text { Tempo para o } \\
\text { armazenamento } \\
\text { refrigerado (horas) }\end{array}$ & $\begin{array}{c}\text { Sólidos solúveis } \\
\text { (SS; \%) }\end{array}$ & $\begin{array}{c}\text { Acidez titulável } \\
\text { (AT; \% ác. málico) }\end{array}$ & $\begin{array}{c}\text { Relação } \\
\text { SS/AT }\end{array}$ & pH & $\begin{array}{c}\text { Textura do } \\
\text { parênquima } \\
\text { externo (N) }\end{array}$ & $\begin{array}{c}\text { Força para } \\
\text { compressão } \\
\text { do fruto (N) }\end{array}$ \\
\hline 0 & 9,03 & 0,982 & 9,2 & 3,7 & 2,93 & 30,8 \\
24 & 8,40 & 0,836 & 10,1 & 3,5 & 2,90 & 26,2 \\
48 & 9,10 & 0,681 & 13,4 & 4,4 & 1,92 & 26,8 \\
\hline Lineary & $\mathrm{ns}$ & $* * *$ & $* * *$ & $* *$ & $*$ & $*$ \\
Quadrático & $\mathrm{ns}$ & $\mathrm{ns}$ & $\mathrm{ns}$ & $*$ & $\mathrm{~ns}$ & $\mathrm{~ns}$ \\
CV $(\%)$ & 6,6 & 8,5 & 9,5 & 6,2 & 18,7 & 9,9 \\
\hline
\end{tabular}

Dados analisados através de contrastes ortogonais polinomiais (linear ${ }^{y}$ e quadrático ${ }^{z}$ ).

ns = não significativo; $* * *$ e $* * *=$ significativo a 5,1 e $0,1 \%$ de probabilidade de erro, respectivamente.

\section{CONCLUSÕES}

Frutos da cultivar Nonante apresentam, em relação às demais cultivares, melhor qualidade quanto aos atributos físico-químicos e de composição mineral (menores teores de $\mathrm{N}$ na polpa) na colheita e menor severidade de escurecimento de polpa após o armazenamento refrigerado. Todas as cultivares apresentam maior redução na AT do que no teor de SS em pós-colheita. Frutos da cultivar Alcântara submetidos ao retardo no armazenamento refrigerado apresentam perda expressiva na qualidade após o armazenamento refrigerado, o mesmo não ocorrendo quando os frutos são submetidos ao dano mecânico na colheita.

\section{AGRADECIMENTOS}

Ao Conselho Nacional de Desenvolvimento Científico e Tecnológico (CNPq) e à Fundação de Amparo à Pesquisa e Inovação do Estado de Santa Catarina (FAPESC), pela concessão de bolsas; à EPAGRI, Estação Experimental de São Joaquim, pelo fornecimento dos frutos; e ao técnico Humberto Nunes Ribeiro, pelo apoio à realização dos experimentos.

\section{REFERÊNCIAS}

AL-HARTHY, A.-A. S. Postharvest treatments to extend the storage life of feijoa (Acca sellowiana). 2010. $161 \mathrm{f}$. Thesis (Doctor of Philosophy in Food Technology) - Massey University, Palmerston North, 2010.

AMARANTE, C.V.T. do; ARGENTA, L.C.; BASSO, C.; SUZIKI, A. Composição mineral de maçãs 'Gala' e 'Fuji' produzidas no Sul do Brasil. Pesquisa Agropecuária Brasileira, Brasília, v.47, n.4, p.550560, 2012.

AMARANTE, C.V.T. do; CHAVES, D.V.; ERNANI, P.R. Análise multivariada de atributos nutricionais associados ao "bitter pit" em maçãs 'Gala'. Pesquisa Agropecuária Brasileira, Brasília, v.41, n.5, p.841-846, 2006.

AMARANTE, C.V.T. do; STEFFENS, C.A.; DUCROQUET, J.P.H.J.; SASSO, A. Qualidade de goiaba serrana em resposta à temperatura de armazenamento e ao tratamento com 1-metilciclopropeno. Pesquisa Agropecuária Brasileira, Brasília, v.43, n.12, p.1683-1689, 2008.

BONTEMPO, P.; MITA, L.; MICELI, M. et al. Feijoa sellowiana derived natural Flavone exerts anti-cancer action displaying HDAC inhibitory activities. The International Journal of Biochemistry \& Cell Biology, Amsterdam, v.39, n.10, p.1902-1914, 2007. 
DURIGAN, M.F.B.; MATIIUZ, B.H.; DURIGAN, J.F. Injúrias mecânicas na qualidade pós-colheita de lima ácida 'Tahiti' armazenada sob condições ambiente. Revista Brasileira de Fruticultura, Jaboticabal, v. 27, n.3, p. 369-372, 2005.

EAST, A.R.; TREJO-ARAYA, X.I.; HERTOG, M.L.A.T.M.; NICHOLSON, S.E.; MAWSON, A.J. The effect of controlled atmospheres on respiration and rate of quality change in 'Unique' feijoa fruit. Postharvest Biology and Technology, Amsterdam, v.53, n.1, p.66-71, 2009.

GONÇALVES, C.A.A.; LIMA, L.C. de O.; LOPES, P.S.N.; PRADO, M.E.T. Caracterização física, físicoquímica, enzimática e de parede celular em diferentes estádios de desenvolvimento da fruta de figueira. Ciência e Tecnologia de Alimentos, Campinas, v.26, n.1, p.220-229, 2006.

HOFFMANN, A.; NACHTIGAL, J.C.; KLUGE, R.A.; BILHALVA, A.B. Influência da temperatura e do polietileno no armazenamento de frutos de goiabeira serrana (Feijoa sellowiana Berg.). Scientia Agricola, Piracicaba, v.51, n.3, p.563-568, 1994.

LETERME, P.; BULDGEN, A.; ESTRADA, F.; LONDONO. Mineral content of tropical fruits and unconventional foods of the Andes and the rain forest of Colombia. Food Chemistry, Maryland Heights, v.95, n.4, p.644-652, 2006.
SANTOS, K.L. dos; DUCROQUET, J.P.H.J.; NAVA, G.; AMARANTE, C.V.T. do; SOUZA, S.N. de; PERONI, N.; GUERRA, M.P.; NODARI, R.O. Orientações para o cultivo da goiabeira-serrana (Acca sellowiana). Florianópolis: Epagri, 2011.44p. (Boletim Técnico, 153).

SCHOTSMANS, W.C.; EAST, A.; THORP, G.; WOOLF, A.B. Feijoa (Acca sellowiana [Berg] Burret). In: YAHIA, E. M. (Ed.). Postharvest biology and technology of tropical and subtropical fruits: cocoa to mango. Cambridge: Woodhead Publishing, 2011. v.3, p.115-133.

THORP, G. Feijoa. In.: JANICK, J., PAULL, R.E. (Ed.). The encyclopedia of fruit \& nuts. London: CABI Publisher, 2006. p.526-534.

VELHO, A.C.; AMARANTE, C.V.T.; ARGENTA, L.C.; STEFFENS, C.A. Influência da temperatura de armazenamento na qualidade pós-colheita de goiabas serranas. Revista Brasileira de Fruticultura, Jaboticabal, v.33, n.1, p.14-20, 2011.

WESTON, R.J. Bioactive products from fruit of the feijoa (Feijoa sellowiana, Myrtaceae): A review. Food Chemistry, Maryland Heights, v.121, n.1, p.923-926, 2010. 